In assuming the office of president, Mr. Sheldon made a statement of policy. The British Association of Chemists is not, nor does it pretend to be, a qualifying body; but it is the only organisation which exists for the sole purpose of looking after the economic interests of the chemical profession. It gives members financial support from its Unemployment Benefit Fund, which has a reserve of more than $£ 42,000$; and it is exploring the possibility of setting up a superannuation scheme which will be transfer. able when a member moves from one firm to another. It is also hoped to extend the unemployment benefit scheme to cover loss of income through sickness or accident. A comprehensive appointments service is provided. The Association aims at recognition by industrial firms, Government departments and public authorities as the appropriate body with which all matters relating to the economic interests and the status of chemists should be discussed. To this end it is registered as a trade union; but it is not in any way associated with any particular political party. An important activity of the Association is the formation of student groups through which students of chemistry can take an interest in matters concerning their present and future economic welfare, and secure the co-operation and advice of the senior members.

\section{New Culture Medium for Penicillium notatum}

Is the absence of supplies of penicillin in Hungary during the War, Dr. E. Rosenthal, of St. Roch's Hospital, Budapest, isolated two strains of what appeared to be Penicillium notatum Westling from which were prepared filtrates exhibiting antibiotic activity against isolated strains of Staphylococcus albus. Since glucose or other forms of sugar required for the usual culture media were extremely difficult to obtain, substitutes were sought. The urine of diabetic patients was ultimately found to provide a good culture medium for the mould, and, for the routine production of penicillin-active filtrates, was adjusted to contain 4 per cent of sugar. The acidity was adjusted to the usual $p H$ of the Czapek-Dox medium and, after filtration and sterilization, the urine was inoculated with the spores of the mould. In comparison with the Czapek-Dox medium, diabetic urine produced in most instances accelerated development of the mould with the appearance of as much as three times the amount of antibiotic activity. Similar results were usually obtained with a medium prepared by the addition of 4 per cent of glucose to normal human urine. The addition to a culture medium of substances such as indol-acetic acid is known to stimulate penicillin production, and the results obtained with diabetic urine are probably to be ascribed to the presence therein of stimulating substances of this and other types.

\section{Disappearance of a Mendel Manuscript}

DR. JARosLav KřžENECKÝ, of the Zootechnical Research Institute and College of Agriculture in Brno, Czechoslovakia, has informed Dr. Herbert C. Hanson, chief of the Agricultural Division, United Nations Relief and Rehabilitation Administration Mission to Czechoslovakia, that Mendel's manuscript "Versuche über Pflanzen Hybriden" has disappeared. This manuscript had been in the custody of the Natural History Society in Brno since 1910, when it was found by Prof. Hugo Iltis in a waste-paper basket in the Society's library. In 1939, when the Germans occupied Brno, Dr. Otto Richter, professor of botany in the German Technical College in Brno, took over the chair of plant physiology in the Faculty of Science in the Masaryk University. All the buildings and facilities of this University were turned over to the German College. Some of the Czech assistants were persuaded to remain under Richter. They have informed Dr. Kř́ženecký that Prof. Richter, after he had taken over the apartments of the Natural History Society, carried Mendel's manuscript about with him in his brief-case. Richter was also a student of Mendel's history and wrote several publications about Mendel during the War. When the Germans were evacuating Brno upon the approach of the Russians, Richter disappeared. It is thought that he may have taken Mendel's manuscript with him either to Germany or Vienna. So far, the whereabouts of Prof. Richter and of the manuscript are unknown. It is to be hoped that further official aid will be given in searching for this interesting document, which should be returned to Brno.

\section{Tibetan Culture}

Trвex has always been a mystery land, and even now little is accurately known of its story. Cheng Te-k'un and D. Michael Sullivan, in No. 6 of the Guidebook Series issued by the West China Union University Museum, Chengtu, Hwasipa, have produced a pamphlet of forty pages intended to supply this need. Much information is given, even if in a rather dull manner and without any illustrations. Anyone wanting to know something of the dry bones of Tibetan history will find much that he is seeking here.

\section{Polar Exploration Exhibition}

An exhibition illustrating the story of polar exploration to the present day is open to the public at the Royal Geographical Society's House (Exhibition Road entrance) during January 4-18 inclusive, 11 a.m. to 4 p.m. daily, except Sundays. The history of polar exploration is shown by paintings, prints, maps and photographs as well as personal relics of famous polar explorers; and a selection of modern equipment, including that used by the Royal Navy, the Army and the Royal Air Force, demonstrates modern technical developments.

\section{Conference on Pulverized Fuel}

A CONFERENCE on pulverized fuel is being organised under the auspices of the Institute of Fuel and will be held in Harrogate during June 3-6. Some fifty papers have been promised from authorities in Great Britain, and contributions are also expected from South Africa, Australia, the United States, France, Holland and Germany. The papers are to be published in a book which will be sent four weeks before the opening session to all who take up membership of the conference. This book will contain, as well as the papers, an index to authors, an index to subjects, and the programme for each session. Each programme will set out the points to be discussed at that session with a cross-index to the comments of the authors upon them. Each session will be devoted almost wholly to discussion, following a short survey outlining the topics for that session. Membership of the conference will be open to anyone interested in pulverized fuel. Particulars can be obtained in due course from the Pulverised Fuel Conference Committee, Institute of Fuel, 18 Devonshire Street, London, W.1. 